J. E. Tooke - L. M. Elston - K. M. Gooding •

C. I. Ball - D. M. Mawson - J. Piper · R. Sriraman •

R. Urquhart · A. C. Shore

\title{
The insulin sensitiser pioglitazone does not influence skin microcirculatory function in patients with type 2 diabetes treated with insulin
}

Received: 13 October 2005 / Accepted: 6 December 2005 / Published online: 1 March 2006

(C) Springer-Verlag 2006

\begin{abstract}
Aims/hypothesis: Insulin resistance is associated with abnormal microvascular function. Treatment with insulin sensitisers may provoke oedema, suggesting microvascular effects. The mechanisms underlying the peripheral oedema observed during glucose-lowering treatment with thiazolidinediones are unclear. Therefore we examined the effect of pioglitazone on microvascular variables involved in oedema formation. Methods: Subjects (40-80 years) with type 2 diabetes and on insulin were randomised to 9 weeks of pioglitazone therapy (30 $\mathrm{mg} /$ day; $n=14)$ or placebo $(n=15)$. The following assessments were performed at baseline and 9 weeks: microvascular filtration capacity; isovolumetric venous pressure; capillary pressure; capillary recruitment following venous or arterial occlusion; postural vasoconstriction; and maximum blood flow. A number of haematological variables were also measured including vascular endothelium growth factor (VEGF), IL-6 and C-reactive protein (CRP). Results: Pioglitazone did not significantly influence any microcirculatory variable as compared with placebo (analysis of covariance [ANCOVA] for microvascular filtration capacity for the two groups, $p=0.26$ ). Mean VEGF increased with pioglitazone $(61.1 \mathrm{pg} / \mathrm{ml})$, but not significantly more than placebo $(9.76 \mathrm{pg} / \mathrm{ml}, p=0.94)$.
\end{abstract}

J. E. Tooke $(\bowtie) \cdot$ L. M. Elston $\cdot$ K. M. Gooding $\cdot$ C. I. Ball

D. M. Mawson - J. Piper - R. Sriraman - A. C. Shore

Institute of Biomedical and Clinical Science,

Peninsula Medical School,

Barrack Road,

Exeter, EX2 5AX, UK

e-mail: john.tooke@pms.ac.uk

Tel.: +44-1392-403064

Fax: +44-1392-403027

R. Urquhart

Research \& Development,

Takeda Europe Research and Development Centre,

London, UK
$\mathrm{HbA}_{1 \mathrm{c}}$ levels and the inflammatory markers IL-6 and CRP decreased with pioglitazone compared with placebo (ANCOVA: $p=0.009, p=0.001$ and $p=0.004$, respectively). Conclusions/interpretation: Pioglitazone improved glycaemic control and inflammatory markers over 9 weeks but had no effect on microcirculatory variables associated with oedema or insulin resistance in type 2 diabetic patients treated with insulin.

Keywords Capillary filtration - Insulin sensitivity · Microcirculation · Oedema · Pioglitazone ·

Thiazolidinediones

Abbreviations ANCOVA: analysis of covariance CRP: C-reactive protein $\cdot$ FPG: fasting plasma glucose $\cdot \mathrm{Kf}$ : microvascular filtration capacity - MBF: maximum blood flow $\cdot \mathrm{PV}$ : postural vasoconstriction $\cdot \mathrm{PVi}$ : isovolumetric venous pressure - TZD: thiazolidinedione - VEGF: vascular endothelium growth factor

\section{Introduction}

Microvascular abnormalities are present in type 2 diabetes $[1,2]$. Microvascular dysfunction precedes development of type 2 diabetes and is associated with insulin resistance, which characteristically predates this condition [3-6]. Two major functional abnormalities seen are: (1) reduced maximum microvascular blood flow, and (2) reduced capillary recruitment in response to vasodilatory stimuli, including insulin [7-9]. Limited skeletal muscle capillary recruitment in response to the vasodilator insulin may contribute to the expression of insulin resistance $[10,11]$.

The thiazolidinedione (TZD) class of drugs, e.g. pioglitazone, improves insulin sensitivity in patients with type 2 diabetes [12, 13], an effect that occurs within 16 weeks in patients on insulin therapy [13]. Given the relationship between insulin resistance and microvascular 
function, the observation that TZDs may provoke peripheral oedema $[13,14]$ raises the possibility that such an occurrence reflects changes in the microvascular parameters associated with changes in insulin sensitivity.

The occurrence of oedema ultimately reflects a disturbance of Starling's forces (capillary hydrostatic or oncotic pressure, tissue fluid hydrostatic or oncotic pressure, the osmotic reflection coefficient, the hydraulic conductivity of the vessel wall and the surface area available for exchange) or of lymphatic function. In the presence of clinical oedema due to other causes, alterations in one or more of these variables has been demonstrated [15-17]. Even in situations of preclinical oedema, increased permeability has been described $[18,19]$ indicating that subtle abnormalities that precede the development of overt oedema are detectable. The present study was designed to investigate subtle changes in these variables.

The rise in capillary pressure in the feet on standing is limited in healthy persons by the postural vasoconstriction (PV) response [20], thereby preventing oedema formation. PV is shown to be impaired by calcium channel blockers [16], the use of which is associated with oedema. As TZDs have been reported to possess calcium channel blocking activity [21], altered PV provides an additional potential mechanism to explain the oedema associated with TZDs.

Oedema has been reported as a side-effect of pioglitazone, particularly in patients receiving concomitant insulin therapy [13], occurring within 2 weeks of initiating TZD treatment and resolving on drug withdrawal [22]. Half of the cases of TZD-induced oedema reported by Niemeyer and Janney [22] occurred within 2 months of drug initiation. All cases of systemic oedema (pretibial or facial) reported in a trial of troglitazone therapy occurred at about 2 months [23]. Patients withdrew early from a 12 -week TZD study due to oedema, and effects on both white blood cell count and haemoglobin levels have been reported to occur with 4 weeks of treatment [24]. These investigators found that many of the actions of pioglitazone occur early and are maintained. Insulin itself is a vasodilator and may thereby exaggerate the microcirculatory haemodynamic effects of TZDs. To be clinically detectable a considerable volume of fluid needs to be present in the interstitium, a situation preceded by a period of more subtle abnormalities of fluid balance which cannot be detected clinically, but which nevertheless indicates marked abnormalities of microcirculatory function $[18,19]$.

The aims of the present study were therefore to investigate whether doses of pioglitazone, which is known to improve insulin sensitivity, alter microcirculatory variables associated with oedema formation and/or insulin resistance in type 2 diabetic patients on insulin therapy.

\section{Subjects and methods}

\section{Study type}

The study was a randomised, placebo-controlled, doubleblind, 9-week study conducted at a single centre in the UK.
It was conducted in accordance with the principles of the Declaration of Helsinki and of Good Clinical Practice, and was approved by the local medical research ethics committee. All patients provided written informed consent and were medically assessed before entering the study.

\section{Subjects}

Male or female patients (aged 40-80 years) with type 2 diabetes treated with stable doses of insulin (alone or with metformin) were recruited. Patients were required to have had stable glycaemic control, as defined by an $\mathrm{HbA}_{1 \mathrm{c}}$ level of $6.5-10 \%$, for at least 2 months prior to study entry. Major exclusion criteria included: type 1 diabetes; peripheral artery disease; severe chronic venous insufficiency; vascular autoimmune disease; myocardial infarction in the preceding 12 months; heart failure (New York Heart Association classification I-IV); uncontrolled hypertension; use of systemic glucocorticoids within the preceding 4 weeks; use of TZDs or sulphonylureas; use of nonsteroidal anti-inflammatory drugs (apart from aspirin at anti-aggregant doses), calcium channel blockers, or diuretics for oedema control; and familial polyposis coli.

After a 2-week run-in period on existing glucoselowering therapy, during which baseline testing was performed, eligible patients were randomised to 9 weeks of double-blind, add-on treatment with oral pioglitazone ( $15 \mathrm{mg}$ once daily, titrated at 2 weeks to $30 \mathrm{mg}$ once daily) or matching placebo. All study medications were produced by Takeda (London, UK). Doses of concomitant insulin and metformin were adjusted during the study, as medically necessary.

\section{Assessments}

Glycaemic control was assessed at baseline and study end by measuring $\mathrm{HbA}_{1 \mathrm{c}}$ and fasting plasma glucose (FPG) levels. $\mathrm{HbA}_{1 \mathrm{c}}$ was determined using HPLC (Tosoh G7 HPLC system; Tosoh Bioscience, Redditch, UK) and FPG was determined using a glucose oxidase method (GODPAP, Roche Modular Analyser; Roche Diagnositics, Lewes, UK). Triglyceride lipid levels were determined using a colorimetric assay (Roche Modular Analyser).

\section{Microcirculatory function}

The following measures of microcirculatory function were assessed at baseline and after 9 weeks: microvascular filtration capacity ( $\mathrm{Kf}$, primary endpoint), isovolumetric venous pressure (PVi), capillary pressure, capillary recruitment, PV response, maximum blood flow (MBF), and blood levels of vascular endothelial growth factor (VEGF), IL-6 and C-reactive protein (CRP). All assessments were performed in a temperature-controlled laboratory (22.0土 $0.5^{\circ} \mathrm{C}$ ) with the patient having fasted from 22:00 $\mathrm{h}$ the 
previous evening and having taken no medication on the morning of the tests.

A venous congestion plethysmography device (Filtrass Angio; DOMED Medizintechnik, Munich, Germany) was used for the non-invasive measurement of $\mathrm{Kf}$ and $\mathrm{PVi}$ in the legs [25]. Briefly, this method measures changes in calf volume in response to a series of small pressure increments $(8 \mathrm{mmHg})$ applied at mid-thigh level using an inflatable cuff. A biphasic response is observed consisting of an initial rapid increase in calf circumference attributable to venous filling when cuff pressure exceeds venous pressure, followed by a gradual increase in volume caused by fluid filtration which occurs when cuff pressure exceeds filtration pressure at the microvascular interface. The slope of the linear relationship between cuff pressure and limb volume (and thus fluid filtration) is termed $\mathrm{Kf}$ [26]. The $x$ axis intercept of filtration capacity slope with the pressure axis is $\mathrm{PVi}$, which is therefore the pressure at which there is neither net filtration nor reabsorption. Reproducibility of the technique is $7.1 \pm 6.3 \%$ (CV) established by testing five individuals on two occasions.

Capillary pressure was measured by the method described by Lewis et al. [17]. A scalpel was used to remove the upper dead layer of opaque stratum corneum from two fingers of the left hand without inducing bleeding or inflammation. The finger was stabilised and a Granuflex ring (Squibb, Hounslow, UK) was placed around the nailfold to retain a pool of $0.9 \%$ saline and thus to aid visualisation of the capillary and measurement of atmospheric pressure. Nailfold capillary pressure was measured using a servo-nulling electrical impedance technique following direct cannulation of the apex of the capillary loop. Reproducibility $(\mathrm{CV})$ of the technique is $5.2 \pm 3.6 \%$, established by testing six individuals on three occasions.

Capillary recruitment was assessed in the finger using capillary video microscopy with the patient supine with their hand at heart level [9]. The finger was placed under the microscope and illuminated with a mercury vapour light. Images of the capillaries at six fields were each recorded on video for $1 \mathrm{~min}$ under resting conditions. The same fields were re-recorded following the inflation of a digital cuff to $50 \mathrm{mmHg}$ for $10 \mathrm{~min}$ (venous occlusion). The number of capillaries visible in the sites was counted and the mean capillary numbers at rest and under venous occlusion were calculated. On an adjacent finger, capillary number was assessed by video under resting conditions and following release of arterial occlusion $(200 \mathrm{mmHg}$ for $4 \mathrm{~min}$ ) applied using a supra-systolic finger cuff. The mean number of continuously perfused capillaries from the two studied sites during the $15 \mathrm{~s}$ before cuff inflation was defined as the 'pre' capillary number; the 'post' value was defined as the number continuously perfused immediately after cuff deflation. The percentage of capillaries recruited was recorded. Reproducibility (CV) for capillary recruitment following venous and arterial occlusion is $13.41 \%$ (range $3-27 \%$ ) and $5.78 \%$ (range $3-11 \%$ ), respectively, for five subjects each tested on three occasions.

Postural vasoconstriction (which limits the rise in capillary hydrostatic pressure in the foot on standing) was assessed by measurement of red cell flux at the dorsum of the foot and the pulp of the great toe using laser Doppler fluximetry (Periflux Pf2b; Perimed, Stockholm, Sweden), as previously described [27]. Measurements were first taken with the subject supine and the foot at heart level, and then for $5 \mathrm{~min}$ with the foot passively lowered to $50 \mathrm{~cm}$ below the heart and the knee bent. Biological zero, i.e. the laser Doppler signal remaining when an ankle cuff was inflated to cause arterial occlusion, was subtracted from the two flux values before PV was calculated. The temperature of the skin of the foot was continuously recorded using an adherent thermocouple (Comark Electronic, Littlehampton, Sussex) at the pulp of the great toe and brachial blood pressure was recorded every 2 min. PV was calculated as: $\mathrm{PV}(\%)=(\mathrm{DF} /$ $\mathrm{HF}) \times 100$, where $\mathrm{DF}=$ mean flux measured with the foot in the dependent position, and $\mathrm{HF}=$ mean flux with the foot at heart level. Thus, the lower the value, the greater the PV response (lower flux is observed under greater vasoconstriction). Reproducibility of the technique was previously assessed in six men measured on three occasions. Skin blood flow reduced to $18.3 \pm 4.5,18.6 \pm 3.1$ and $19.2 \pm 4.3 \%$ of supine values at each visit.

MBF was measured at the dorsum of the foot by laser Doppler fluximetry after the skin had been heated to $42^{\circ} \mathrm{C}$ for $30 \mathrm{~min}$ using a small brass heater of $1 \mathrm{~cm}$ diameter [4]. The average of eight 30 -s flux measurements at different skin areas over the heated site was calculated. Reproducibility (CV) of the technique was $6.6 \%$ established by testing three persons five times.

Blood pressure was measured at the site of the left brachial artery using a semi-automatic blood pressure recorder (Critikon Dinamap, FL, USA). Five measurements were obtained at 1-min intervals and the mean of the final three readings was taken to be the representative blood pressure.

Blood levels of VEGF, IL-6 and CRP were measured by ELISA (VEGF Quantikine kit and IL-6 Quantikine HS kit [R\&D Systems, Abingdon, UK] and CRP kit [Autogen Bioclear UK, Wilts, UK]). All blood samples were obtained after assessment of microcirculatory function.

\section{Statistical analysis}

It was estimated that 14 patients per arm would be required to detect a difference between the two treatment groups in the change from baseline in Kf of at least $0.4 \times 10^{-3} \mathrm{ml} \mathrm{min}^{-1}$ $100 \mathrm{ml}^{-1} \mathrm{mmHg}^{-1}(0.47 \mathrm{SDs})$ with $90 \%$ power at the $5 \%$ significance level. For comparison, a difference of $0.8 \times 10^{-3} \mathrm{ml} \mathrm{min}^{-1} 100 \mathrm{ml}^{-1} \mathrm{mmHg}^{-1}$ was noted between non-oedematous patients with congestive heart failure compared with controls [19].

Changes from baseline in endpoints were assessed using analysis of covariance (ANCOVA), with the factor as treatment group and the baseline value as covariate (using SPSS version 11.5). SDs, 95\% CIs, and two-sided $p$ values ( $5 \%$ significance level) were calculated for the change from baseline and the difference between groups. It was found 
that data on PV (dorsum of the foot) and VEGF, IL-6 and CRP levels were not normally distributed. Log-transformation resulted in normalisation of these variables and ANCOVA was performed as above.

\section{Results}

\section{Subject characteristics}

Thirty-nine patients were screened, of whom 29 were randomised to study medication, 14 with pioglitazone and 15 with placebo. All patients completed the study. The patients had a mean age of 61 years, $72 \%$ were male and all but one were of white European origin. The pioglitazone and placebo groups were well matched with regard to their demographic and clinical characteristics (Table 1) with no variable demonstrating a significant difference between the groups (as measured by unpaired $t$-test). The medical histories of both groups were typical for populations of those with type 2 diabetes. Ten patients in the pioglitazone group (71\%) and 11 in the placebo group (73\%) were taking current anti-hypertensive therapy.

Table 1 Baseline characteristics

\begin{tabular}{|c|c|c|}
\hline Characteristic & Pioglitazone & Placebo \\
\hline Male, $n(\%)$ & $11(78.6)$ & $10(66.7)$ \\
\hline Female, $n(\%)$ & $3(21.4)$ & $5(33.3)$ \\
\hline Age (years) & $64.0 \pm 7.9$ & $59.0 \pm 6.3$ \\
\hline Height (cm) & $170.0 \pm 8.6$ & $170.0 \pm 7.8$ \\
\hline Weight (kg) & $84.1 \pm 14.5$ & $89.5 \pm 9.5$ \\
\hline BMI $\left(\mathrm{kg} / \mathrm{m}^{2}\right)$ & $28.9 \pm 4.1$ & $30.9 \pm 2.9$ \\
\hline $\begin{array}{l}\text { Systolic blood pressure } \\
(\mathrm{mmHg})\end{array}$ & $143 \pm 13$ & $135 \pm 13$ \\
\hline $\begin{array}{l}\text { Diastolic blood pressure } \\
(\mathrm{mmHg})\end{array}$ & $78 \pm 7$ & $76 \pm 8$ \\
\hline $\mathrm{HbA}_{1 \mathrm{c}}(\%)^{\mathrm{a}}$ & $7.8 \pm 0.8$ & $8.5 \pm 0.9$ \\
\hline FPG (mmol/l) & $8.0 \pm 2.7$ & $10.0 \pm 3.6$ \\
\hline $\begin{array}{l}\text { Insulin dose } \\
\text { (range, U/day) }\end{array}$ & $25-136$ & $28-104$ \\
\hline $\begin{array}{l}\text { Patients taking metformin, } \\
n(\%)\end{array}$ & $8(57.1)$ & $8(53.3)$ \\
\hline $\begin{array}{l}\text { Metformin dose } \\
\text { (range, } \mathrm{mg} / \text { day) }\end{array}$ & $1,500-3,000$ & $1,000-3,000$ \\
\hline $\begin{array}{l}\text { Plasma triglycerides } \\
(\mathrm{mmol} / \mathrm{l})\end{array}$ & $1.81 \pm 1.65$ & $1.58 \pm 0.64$ \\
\hline $\begin{array}{l}\text { Vibratory sensory threshold } \\
>25 \mathrm{~V}, n(\%)\end{array}$ & $6(42.9)$ & $5(33.3)$ \\
\hline $\begin{array}{l}\text { Albumin:creatinine ratio } \\
>3.0, n(\%)\end{array}$ & $3(21.4)$ & $2(13.3)$ \\
\hline $\begin{array}{l}\text { Retinopathy (none/background/ } \\
\text { maculopathy/stage unknown) }\end{array}$ & $3 / 6 / 4 / 1$ & $8 / 4 / 2 / 1$ \\
\hline
\end{tabular}

Continuous data expressed as means $\pm \mathrm{SD}$

No significant difference was found for any variable by unpaired $t$-test

${ }^{\mathrm{a}} p=0.06$
Glycaemic control

Eight patients in each group were concomitantly treated with metformin at constant doses during the study and, at baseline, the mean $\mathrm{HbA}_{1 \mathrm{c}}$ and FPG levels were lower in the pioglitazone group than in the placebo group, but the difference was not significant. At study end, the mean $\mathrm{HbA}_{1 \mathrm{c}}$ decreased by $-0.40 \pm 0.56 \%$ in the pioglitazone group compared with no change in the placebo group $(0.00 \pm$ $0.48 \%$ ), ANCOVA, $p=0.009$.

The daily insulin dose was altered during the study in nine patients in the pioglitazone group and eight in the placebo group. Mean insulin dose change was $-6.7 \pm 10.5$ units for the pioglitazone group vs placebo $+1.1 \pm 5.7$ units (ANCOVA, $p=0.03$ ). Patients who were on pioglitazone had a greater increase in weight of $1.40 \pm 1.65 \mathrm{~kg}$ vs placebo $0.05 \pm 0.72 \mathrm{~kg}$ (ANCOVA, $p=0.04$ ). There was no significant difference in the change in triglyceride levels for the pioglitazone and placebo group $(-0.22 \mathrm{vs}-0.01 \mathrm{mmol} / 1$, respectively; ANCOVA, $p=0.26$ ).

\section{Inflammatory markers}

Measures of both IL- 6 and CRP decreased significantly in those taking pioglitazone compared with those taking placebo (mean change from baseline for IL-6: $-0.63 \pm 1.70$ vs $0.08 \pm 1.63 \mathrm{pg} / \mathrm{ml}, p=0.001$; CRP: $-5.45 \pm 15.59$ vs $-2.72 \pm$ $7.46 \mathrm{mg} / \mathrm{l}, p=0.004$ ) (Table 2).

Microcirculatory function

Data relating to microcirculatory function at baseline and change over 9 weeks are shown in Table 2 .

\section{Kf and PVi}

At baseline, mean $\mathrm{Kf}$ values were similar in the pioglitazone and placebo groups and after 9 weeks the mean change from baseline in $\mathrm{Kf}$ was not significantly different for the two groups: $-0.15 \times 10^{-3} \mathrm{ml} \mathrm{min}^{-1} 100 \mathrm{ml}^{-1}$ $\mathrm{mmHg}{ }^{-1}$ with pioglitazone, compared with $+0.19 \times 10^{-3} \mathrm{ml}$ $\mathrm{min}^{-1} 100 \mathrm{ml}^{-1} \mathrm{mmHg}^{-1}$ with placebo (ANCOVA, $p=0.261$ ). The mean PVi at baseline was slightly higher in the pioglitazone group than in the placebo group and the groups showed no significant difference in their mean change from baseline after 9 weeks $(-3.25$ and $-1.15 \mathrm{mmHg}$, respectively, $p=0.407$ ).

\section{Capillary pressure}

Mean capillary pressures did not differ at baseline and there was no statistically significant difference in the mean change from baseline $(+0.33 \mathrm{mmHg}$ in the pioglitazone group and $+0.34 \mathrm{mmHg}$ in the placebo group; ANCOVA, $p=0.987$ ). 
Table 2 Baseline values for microcirculation variables and changes from baseline in type 2 diabetic patients treated with pioglitazone or placebo for 9 weeks

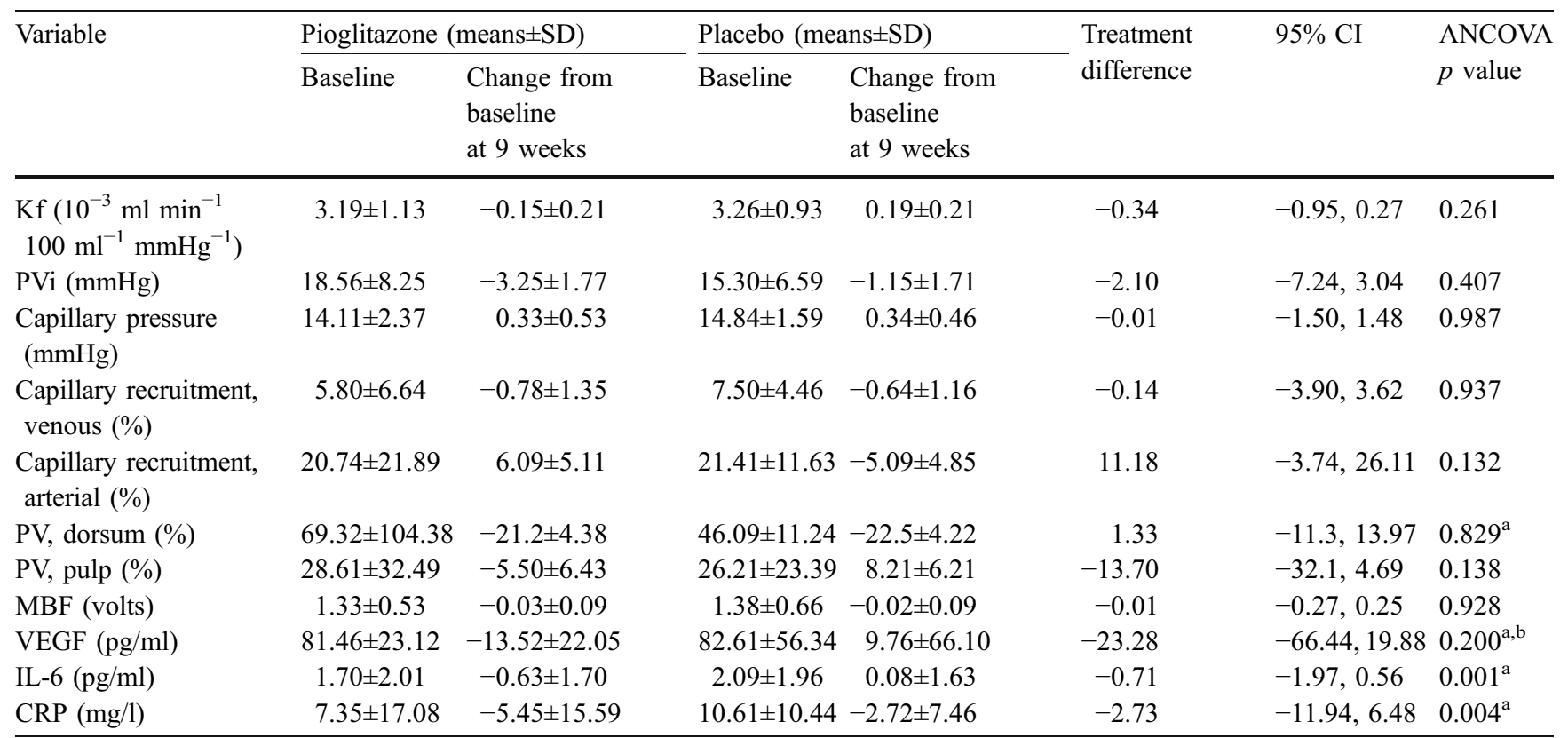

${ }^{a}$ ANCOVA performed on log-transformed data

${ }^{\mathrm{b}}$ Outlier in pioglitazone group removed for VEGF data in table; outlier value baseline $61.9 \mathrm{pg} / \mathrm{ml}$, post-pioglitazone $943.5 \mathrm{pg} / \mathrm{ml}$, $p=0.940$ with outlier included

\section{Capillary recruitment}

The mean baseline values for the increase in capillary number during venous occlusion were slightly lower for pioglitazone $(5.8 \%)$ than placebo $(7.5 \%)$ and the mean change from baseline for the groups was -0.78 vs $-0.64 \%$, respectively, (ANCOVA, $p=0.937$ ). Capillary recruitment following arterial occlusion, which has previously been linked to insulin sensitivity, showed no significant treatment difference between the groups (ANCOVA, $p=0.132$ ).

\section{Postural vasoconstriction}

There was no significant difference between the groups in the change from baseline in PV, measured by ANCOVA, at either the dorsum of the foot $(-21.2 \%$ for pioglitazone vs $-22.5 \%$ for placebo, $p=0.829$ ) or the pulp of the great toe $(-5.50$ vs $+8.21 \%, p=0.138)$.

\section{MBF}

Baseline mean MBF values were similar in the two groups and showed no change during the study $(-0.03 \mathrm{~V}$ for pioglitazone vs $-0.02 \mathrm{~V}$ for placebo; ANCOVA, $p=0.928)$.

\section{Blood pressure}

Neither systolic nor diastolic blood pressure changed in the pioglitazone group as compared with the placebo group over the 9-week period (ANCOVA, $p=0.144$ and $p=0.332$, respectively).

\section{VEGF}

Blood levels of VEGF increased from baseline in the pioglitazone group $(+61.07 \pm 259.23 \mathrm{pg} / \mathrm{ml})$, primarily due to outlier data in one patient, without whom there was a slight fall (Table 2). This change did not differ significantly from that observed with placebo $(+9.76 \pm 66.10 \mathrm{pg} / \mathrm{ml}$, $p=0.940$ ) and analysis following the exclusion of the outlier data did not change the pattern of the results $(p=0.20)$.

\section{Oedema}

Only one patient in the pioglitazone group and one in the placebo group reported peripheral oedema. Despite multiple attempts, Kf, PVi and capillary recruitment were unobtainable from the individual in the pioglitazone group due to unusual capillary anatomy and involuntary patient movement artefacts.

\section{Discussion}

Pioglitazone, in common with other drugs in the TZD class, reduced the inflammatory marker CRP associated with insulin resistance [28-30]. In addition, IL-6 levels were significantly reduced, supporting the anti-inflamma- 
tory property of pioglitazone. In the present study, pioglitazone increased insulin sensitivity, as judged by a reduction in the patients' insulin dose in the context of improved glycaemic control over the 9-week period. Despite previous findings of increased VEGF after 4 weeks of treatment with pioglitazone [31], suggesting that it may be the mediator of permeability changes, no significant changes in VEGF were observed.

Despite these indications of increased insulin sensitivity during pioglitazone therapy of this duration, no changes in microvascular function were demonstrated, suggesting that under these conditions insulin sensitivity is not closely linked to capillary number or capillary recruitment as has been previously demonstrated [9], although a type 2 error cannot be ruled out for capillary recruitment after arterial occlusion. No changes were observed in skin maximum microvascular blood flow, a variable strongly associated with a variety of insulin-resistant states that correlates with measures of insulin sensitivity. This could imply that either the association is non-causal or that the period of TZD drug exposure in this study was inadequate to allow remodelling of the microcirculation to permit a greater hyperaemic response. Such an explanation has been advanced to explain why in type 2 diabetic patients no changes in $\mathrm{MBF}$ were observed after 3 months of improved glycaemic control, whereas changes were observed after 1 year [32]. In support of this, intensive blood-glucose control reduces the risk of microvascular complications and the extent of the risk reduction increases with years of improved glycaemic control (UKPDS 33 trial) [33].

The administration of pioglitazone to patients with concomitant administration of insulin may increase the frequency of oedema in pioglitazone recipients [13]. Oedema formation is the result of filtration from blood vessels exceeding lymph flow for a sustained period. Thus increasing filtration or reductions in lymph flow would result in oedema. However, in the present study only one patient in the placebo group and one patient in the pioglitazone group reported oedema. The $\mathrm{Kf}$ techniques used in the present study are adequate to detect small, subclinical increases in transvascular fluid movement, as seen in healthy volunteers during hormonal changes associated with the menstrual cycle [18] or in non-oedematous patients with early stages of heart failure [19]. Nevertheless, in this group of patients receiving pioglitazone no subtle changes in the major factors that influence fluid extravasation, that is capillary pressure (which forces fluid out of the capillary) and $\mathrm{Kf}$ (which is the measure of the permeability of the capillary wall), were demonstrated. Furthermore pioglitazone did not impair PV, an oedemapreventing mechanism which has been demonstrated previously to be impaired during the use of calcium channel blockers [16].

Thus in this group of patients with type 2 diabetes mellitus neither oedema nor increases in microvascular permeability or haemodynamics that can predispose towards oedema were demonstrated. Importantly, given the concerns regarding the potential for TZDs to provoke features of cardiac failure [34-36], none of the abnormal- ities in microvascular parameters previously observed in early heart failure [19] occurred following treatment.

It is conceivable that the absence of significant change in parameters that could predispose to oedema was due to a type 2 error but the sample size employed in this study was adequate to discern the cause of hyperfiltration in other oedema studies [18, 19]. Pioglitazone-induced overt oedema occurs frequently within this study's treatment period of 9 weeks [22]. It is therefore unlikely that the lack of effect on microvascular parameters that detect preclinical subtle changes in fluid dynamics is due to inadequate treatment duration. An alternative explanation may be that TZDs may not in fact influence transcapillary fluid flux in all individuals, reaching clinical proportions in a significant minority, but that instead oedema may only be occurring in a susceptible subgroup with a pre-existing predisposition. Case-control studies of patients with and without oedema would be necessary to test such an assertion.

In conclusion, treatment with pioglitazone had no deleterious effects on microcirculatory variables associated with transvascular movement of fluid, (capillary pressure, filtration capacity or PV), in type 2 diabetic patients treated with insulin.

Acknowledgements This study was supported by Takeda Europe Research and Development Centre Ltd (London, UK) and Eli Lilly and Company (Indianapolis, IN, USA).

\section{References}

1. Lim SC, Caballero AE, Arora S et al (1999) The effect of hormonal replacement therapy on the vascular reactivity and endothelial function of healthy individuals and individuals with type 2 diabetes. J Clin Endocrinol Metab 84:4159-4164

2. Tsujimoto G (2000) Impaired coronary microvascular function in diabetics. Ann Nucl Med 14:165-172

3. Caballero AE, Arora S, Saouaf R et al (1999) Microvascular and macrovascular reactivity is reduced in subjects at risk for type 2 diabetes. Diabetes 48:1856-1862

4. Jaap AJ, Hammersley MS, Shore AC, Tooke JE (1994) Reduced microvascular hyperaemia in subjects at risk of developing type 2 (non-insulin-dependent) diabetes mellitus. Diabetologia 37:214-216

5. Jaap AJ, Shore AC, Tooke JE (1997) Relationship of insulin resistance to microvascular dysfunction in subjects with fasting hyperglycaemia. Diabetologia 40:238-243

6. Wong TY, Klein R, Sharrett AR et al (2002) Retinal arteriolar narrowing and risk of diabetes mellitus in middle-aged persons. JAMA 287:2528-2533

7. Tooke JE (2000) Possible pathophysiological mechanisms for diabetic angiopathy in type 2 diabetes. J Diabetes Complications 14:197-200

8. Tooke JE, Hannemann MM (2000) Adverse endothelial function and the insulin resistance syndrome. J Intern Med 247:425-431

9. Serne EH, Stehouwer CD, ter Maaten JC et al (1999) Microvascular function relates to insulin sensitivity and blood pressure in normal subjects. Circulation 99:896-902

10. Vincent MA, Clerk LH, Lindner JR et al (2004) Microvascular recruitment is an early insulin effect that regulates skeletal muscle glucose uptake in vivo. Diabetes 53:1418-1423

11. Wallis MG, Wheatley CM, Rattigan S, Barrett EJ, Clark AD, Clark MG (2002) Insulin-mediated hemodynamic changes are impaired in muscle of Zucker obese rats. Diabetes 51:3492-3498 
12. Vasudevan AR, Balasubramanyam A (2004) Thiazolidinediones: a review of their mechanisms of insulin sensitization, therapeutic potential, clinical efficacy, and tolerability. Diabetes Technol Ther 6:850-863

13. Rosenstock J, Einhorn D, Hershon K, Glazer NB, Yu S (2002) Efficacy and safety of pioglitazone in type 2 diabetes: a randomised, placebo-controlled study in patients receiving stable insulin therapy. Int J Clin Pract 56:251-257

14. Mudaliar S, Chang AR, Henry RR (2003) Thiazolidinediones, peripheral edema, and type 2 diabetes: incidence, pathophysiology, and clinical implications. Endocr Pract 9:406-416

15. Fahr G, Ershler I (1941) Studies of the factors concerned in edema formation. II The hydrostatic pressure in the capillaries during edema formation in right heart failure. Ann Intern Med 15:798-810

16. Williams SA, Rayman G, Tooke JE (1989) Dependent oedema and attenuation of postural vasoconstriction associated with nifedipine therapy for hypertension in diabetic patients. Eur J Clin Pharmacol 37:333-335

17. Lewis DM, Tooke JE, Beaman M, Gamble J, Shore AC (1998) Peripheral microvascular parameters in the nephrotic syndrome. Kidney Int 54:1261-1266

18. Hassan AA, Carter G, Tooke JE (1990) Postural vasoconstriction in women during the normal menstrual cycle. Clin Sci (Lond) 78:39-47

19. Mahy IR, Shore AC, Smith LD, Tooke JE (1995) Disturbance of peripheral microvascular function in congestive heart failure secondary to idiopathic dilated cardiomyopathy. Cardiovasc Res 30:939-944

20. Hassan AA, Tooke JE (1988) Mechanism of the postural vasoconstrictor response in the human foot. Clin Sci (Lond) 75:379-387

21. Nakamura Y, Ohya Y, Onaka U, Fujii K, Abe I, Fujishima M (1998) Inhibitory action of insulin-sensitizing agents on calcium channels in smooth muscle cells from resistance arteries of guinea-pig. Br J Pharmacol 123:675-682

22. Niemeyer NV, Janney LM (2002) Thiazolidinedione-induced edema. Pharmacotherapy 22:924-929

23. Bando Y, Ushiogi Y, Okafuji K, Toya D, Tanaka N, Fujisawa M (1999) Troglitazone combination therapy in obese type 2 diabetic patients poorly controlled with alpha-glucosidase inhibitors. J Int Med Res 27:53-64

24. Saad MF, Greco S, Osei K et al (2004) Ragaglitazar improves glycemic control and lipid profile in type 2 diabetic subjects: a 12-week, double-blind, placebo-controlled dose-ranging study with an open pioglitazone arm. Diabetes Care 27:1324-1329
25. Christ F, Bauer A, Brugger D, Niklas M, Gartside IB, Gamble J (2000) Description and validation of a novel liquid metalfree device for venous congestion plethysmography. J Appl Physiol 89:1577-1583

26. Gamble J, Christ F, Gartside IB (1998) Human calf precapillary resistance decreases in response to small cumulative increases in venous congestion pressure. J Physiol 507:611-617

27. Shore AC, Price KJ, Sandeman DD, Tripp JH, Tooke JE (1994) Posturally induced vasoconstriction in diabetes mellitus. Arch Dis Child 70:22-26

28. Haffner SM, Greenberg AS, Weston WM, Chen H, Williams K, Freed MI (2002) Effect of rosiglitazone treatment on nontraditional markers of cardiovascular disease in patients with type 2 diabetes mellitus. Circulation 106:679-684

29. Mohanty P, Aljada A, Ghanim H et al (2004) Evidence for a potent antiinflammatory effect of rosiglitazone. J Clin Endocrinol Metab 89:2728-2735

30. Satoh N, Ogawa Y, Usui T et al (2003) Antiatherogenic effect of pioglitazone in type 2 diabetic patients irrespective of the responsiveness to its antidiabetic effect. Diabetes Care 26:2493-2499

31. Baba T, Shimada K, Neugebauer S, Yamada D, Hashimoto S, Watanabe T (2001) The oral insulin sensitizer, thiazolidinedione, increases plasma vascular endothelial growth factor in type 2 diabetic patients. Diabetes Care 24:953-954

32. Jaap AJ, Pym CA, Seamark C, Shore AC, Tooke JE (1995) Microvascular function in type 2 (non-insulin-dependent) diabetes: improved vasodilation after one year of good glycaemic control. Diabet Med 12:1086-1091

33. UK Prospective Diabetes Study (UKPDS) Group (1998) Intensive blood-glucose control with sulphonylureas or insulin compared with conventional treatment and risk of complications in patients with type 2 diabetes (UKPDS 33). Lancet 352:837-853

34. Scheen AJ (2004) Combined thiazolidinedione-insulin therapy: should we be concerned about safety? Drug Saf 27:841-856

35. Marceille JR, Goins JA, Soni R, Biery JC, Lee TA (2004) Chronic heart failure-related interventions after starting rosiglitazone in patients receiving insulin. Pharmacotherapy 24:1317-1322

36. Belcher G, Lambert C, Goh KL, Edwards G, Valbuena M (2004) Cardiovascular effects of treatment of type 2 diabetes with pioglitazone, metformin and gliclazide. Int J Clin Pract 58:833-837 